\title{
Rate and predictors for non-attendance of patients undergoing hospital outpatient treatment for chronic diseases: a register- based cohort study
}

Donna Lykke Wolff ${ }^{1,2^{*}}$ (D) Frans Boch Waldorff ${ }^{3}$, Christian von Plessen ${ }^{4,5}$, Christian Backer Mogensen ${ }^{1,2}$, Thomas Lund Sørensen ${ }^{6}$, Kim Christian Houlind ${ }^{2,7}$, Søren Bie Bogh ${ }^{8}$ and Katrine Hass Rubin ${ }^{8,5}$

\begin{abstract}
Background: Failure to keep medical appointments results in inefficiencies and, potentially, in poor outcomes for patients. The aim of this study is to describe non-attendance rate and to investigate predictors of non-attendance among patients receiving hospital outpatient treatment for chronic diseases.

Methods: We conducted a historic, register-based cohort study using data from a regional hospital and included patients aged 18 years or over who were registered in ongoing outpatient treatment courses for seven selected chronic diseases on July 1, 2013. A total of 5895 patients were included and information about their appointments was extracted from the period between July 1, 2013 and June 30, 2015. The outcome measure was occurrence of non-attendance. The associations between non-attendance and covariates (age, gender, marital status, education level, occupational status, specific chronic disease and number of outpatient treatment courses) were investigated using multivariate logistic regression models, including mixed effect.

Results: During the two-year period, 35\% of all patients (2057 of 5895 patients) had one or more occurrences of non-attendance and 5\% of all appointments (4393 of 82,989 appointments) resulted in non-attendance. Significant predictors for non-attendance were younger age (OR 4.17 for $18 \leq 29$ years as opposed to $80+$ years), male gender (OR 1.35), unmarried status (OR 1.39), low educational level (OR 1.18) and receipt of long-term welfare payments (OR 1.48). Neither specific diseases nor number of treatment courses were associated with a higher non-attendance rate.

Conclusions: Patients undergoing hospital outpatient treatments for chronic diseases had a non-attendance rate of 5\%. We found several predictors for non-attendance but undergoing treatment for several chronic diseases simultaneously was not a predictor. To reduce non-attendance, initiatives could target the groups at risk.
\end{abstract}

Trial registration: This study was approved by the Danish Data Protection Agency (Project ID 18/35695).

Keywords: Non-attendance, No-show, Attendance rate, Chronic patients, Hospital outpatient clinic, Appointments, Predictors

\footnotetext{
* Correspondence: donna.wolff@rsyd.dk

${ }^{1}$ Hospital of Southern Denmark, DK-6200 Aabenraa, Denmark

2Department of Regional Health Research, University of Southern Denmark,

Winsløwparken 19, DK-5000 Odense C, Denmark

Full list of author information is available at the end of the article
}

(c) The Author(s). 2019 Open Access This article is distributed under the terms of the Creative Commons Attribution 4.0 International License (http://creativecommons.org/licenses/by/4.0/), which permits unrestricted use, distribution, and reproduction in any medium, provided you give appropriate credit to the original author(s) and the source, provide a link to the Creative Commons license, and indicate if changes were made. The Creative Commons Public Domain Dedication waiver (http://creativecommons.org/publicdomain/zero/1.0/) applies to the data made available in this article, unless otherwise stated. 


\section{Background}

Patients who do not attend scheduled appointments in hospital outpatient clinics are a challenge for the health care system. Non-attendance is resource demanding, as missed appointments remain unused and new bookings must be made. Studies have associated non-attendance with an increased risk for hospitalizations and emergency department visits [1, 2]. Further, non-attendance may interrupt continuity of care resulting in reduced health outcomes e.g. impaired diabetes $[1,3,4]$ and hyperlipidemia management [1].

A recent systematic review including studies in primary care and specialty clinics showed an average nonattendance rate of $23 \%$ with large variations according to medical specialties and continents [5]. Studies in Denmark have shown non-attendance rates of up to $14 \%[6,7]$.

Research has often focused on non-attendance rates from the perspective of clinics [6, 8-12]; this study has chosen to focus on patients with chronic diseases. In the US and Europe, studies have reported that more than $40 \%$ of the population suffer from a chronic disease and approximately $20 \%$ live with multiple chronic diseases [13-17]. The prevalence of people with chronic diseases is expected to increase in the future as a result of aging populations, changed lifestyle and advances in healthcare $[16,18]$. Patients with chronic diseases are usually in contact with the health care system for many years and the management of chronic disease accounts for approximately $80 \%$ of the health care budgets of Europe and the US $[15,17,19]$. Patients with multiple chronic diseases comprise up to $71 \%$ of the total health care budget $[15,17]$.

As economic resources are limited and workforces in the health care sector are under pressure from the rising demands posed by the increasing prevalence of patients with chronic diseases, there is an urgent need to manage chronic diseases more efficiently [20,21]. One area of interest in this pursuit could be the reduction of resources spent on non-attendance [22].

In Denmark, the majority of patients with chronic diseases are managed by general practitioners, while patients with more complex diseases are referred for specialist treatment to hospital outpatient clinics [23, 24]. Knowledge about the prevalence of non-attendance and an understanding of its predictors may help to target interventions for optimizing attendance rates in this group of patients in need of long-term health care.

Many predictors of non-attendance have been examined as shown in a recent systematic review [5] but studies have often reported conflicting results as a consequence of the influences of patients, providers, and cultural contexts. In general, non-attendance may more often be predicted in those who are male, are young, are of a lower socioeconomic status, live a long distance from the clinic, have a prior history of non-attendance and have a long interval between the time at which their appointment was scheduled to the actual appointment date [5]. We find that there is a lack of studies on the predictive value of having specific diseases or several diseases. We are only aware of one such study, which found that patients with cardiac conditions have a lower non-attendance rate than those with other diseases [25].

Therefore, the aim of this study is to investigate nonattendance by patients undergoing hospital outpatient treatment for chronic disease. More specifically, the current project addresses the following research questions: First, what is the non-attendance rate of patients undergoing hospital outpatient treatment for chronic disease? Second, what are the predictors for nonattendance among this group, especially if undergoing treatment for several concurrent chronic diseases is a predictor for non-attendance?

\section{Methods \\ Study population and setting}

This study is a historic register-based cohort study. We included patients aged 18 years or older who were undergoing outpatient treatment for one or more selected common chronic diseases.

The common chronic diseases were chosen according to those defined as major by the Danish Health Authority and frequently encountered in hospital outpatient settings [26-28].

We included patients with type 1 diabetes mellitus (corresponding ICD-10 code: E10), type 2 diabetes mellitus (E11), heart failure (I50), other chronic obstructive pulmonary disease (COPD) (J44), asthma (J45), rheumatoid arthritis (M05), and osteoporosis (M80 and M81). Patients had to be in ongoing treatment on July 1, 2013 at Hospital Lillebaelt (Denmark).

Hospital Lillebaelt is a regional hospital with a rural and urban catchment population of nearly 300,000 inhabitants [29]. Information on patient appointments was extracted for the period from July 1, 2013 to June 30, 2015.

\section{Data sources}

The Danish National Health Service provides access to tax-financed health care for Denmark's 5.8 million citizens [30]. All Danish hospitals, public and private, report inpatient and outpatient contacts to the National Patient Register (NPR), which holds longitudinal data derived from the electronic medical records of all inpatients of Danish hospitals since 1977 and outpatients since 1994. NPR contains discharge diagnosis codes according to ICD-8 from 1977 to 1993 and adhering to ICD-10 from 1994 onwards [31]. Since 2000, it has also served as the basis for reimbursement via the Diagnostic Related Group system [32]. NPR comprises information on 
appointments that are actualized in attendance. However, NPR does not hold information on non-attendance as hospitals are not reimbursed for non-attended appointments. NPR was used to extract the study population and to obtain information on the patients' age and gender as well as on all outpatient appointments during the study period.

As non-attendance is not registered in the NPR, we used information from Hospital Lillebaelt, where nonattendance is documented in the electronic medical records. Occurrences of non-attendance are registered on a daily basis, as health providers construct a schedule based on whether patients have attended, canceled, rebooked, or have not attended appointments. Nonattendance is not registered for the first appointment of the hospital outpatient treatment course.

Further, we gathered information on patients' marital status from the Danish Civil Registration System [33], on their educational levels from the Danish Education registers [34], and on their occupational status and income from Danish registers on personal income and transfer payments at Statistics Denmark [35]. The links between data from different data sources are made possible using the unique 10-digit identification number assigned to all Danish citizens at birth or at first immigration [33].

\section{Outcome}

The outcome variable was non-attendance. One appointment with or without attendance was included daily. If patients had two appointments on the same day with one registered as attendance and one registered as nonattendance, we categorized this day as attendance, as the non-attendance may have been caused by the hospital; for example, by a prolonged visit in one clinic or by a reservation of for medical imaging that was not used.

\section{Explanatory variables}

Explanatory variables were chosen based on their influence on non-attendance according to previous studies [5]. Further, we included the variables "specific chronic disease" and "number of outpatient treatment courses" as we wanted to know the influence of disease and treatment characteristics. Information on the following explanatory variables was extracted:

- Age (categorized into 10-year intervals). We used the patient age on July 1, 2013.

- Gender (categorized as male/female).

- Marital status (categorized as unmarried/married). The term "married" was used when patients were married or in a registered relationship on July 1 , 2013. If no information existed on patients on the date of interest, we used their latest status.
- Educational level (categorized as basic (primary school)/vocational or upper secondary /further or higher education/unknown). For each patient, the highest completed level of education in 2013 was selected.

- Occupational status (categorized as student/ affiliated with the labor marked/short-term welfare payment/long-term welfare payment/disability pension/pension/unknown). Here, "short-term welfare payment" comprises individuals who were temporarily on a social income; for example, because of illness or maternity leave. "Long-term welfare payment" connotes individuals who received a social income for a longer period. "Disability pension" refers to individuals with a permanently reduced working capacity and a permanent social income. "Pension" describes individuals both on a pension and on an early pension. In our cohort, the retirement age was 65 years. The early pension (a self-paid settlement) can be received up to 5 years prior to the official retirement age. Information on this variable is reported on yearly basis and we extracted our data in 2013.

- Specific chronic disease (categorized as type 1 diabetes mellitus/type 2 diabetes mellitus/heart failure/COPD/asthma/rheumatoid arthritis/ osteoporosis). Patients were categorized into one or more of the disease categories based on information about which outpatient treatment courses they were undertaking at Hospital Lillebaelt on July 1, 2013.

\section{- Number of outpatient treatment courses} (categorized as $1 / 2+$ ). This was based on the number of specific hospital outpatient treated chronic diseases (out of the seven selected diseases) that each patient was undergoing on July 1, 2013.

\section{Statistical analyses} Analyses on the patient level

Patients were categorized as "attenders" if they attended all appointments during the 2 years and "non-attenders" if they missed one or more appointments. We described the patient characteristics of attenders and nonattenders using numbers and percentages and assessed their differences using chi-square tests.

\section{Analyses on the appointment level}

We reported non-attendance as a rate in proportion to appointments. We described patient characteristics both for appointments with attendance and for appointments with non-attendance. The outcome was reported in numbers and percentages and the differences were assessed using chi-square tests.

Associations between non-attendance and covariates were investigated using univariate and multivariate logistic 
regression models, including mixed effects to account for patients with multiple appointments. In the first multivariate logistic regression, we adjusted for age, gender, marital status, education level, occupational status, and specific chronic diseases. In the second multivariate logistic regression, we adjusted for the same variables except for specific chronic disease and we added the number of outpatient treatment courses. We used the Akaike information criterion (AIC) to choose the best model for our primary outcome regression.

All analyses were performed using Stata version 15 (StataCorp, College Station, TX, USA) and $p$-values of less than 0.05 were regarded as statistically significant.

\section{Ethics}

The study did not involve any direct contact with patients or access to patient files. Thus, informed consent or ethical approval were not required [36]. The study was registered with the Danish Data Protection Agency (J.nr. 18/35695).

\section{Results}

On July 1, 2013, 46,975 patients were in hospital outpatient treatment at Hospital Lillebaelt (see Fig. 1: Flowchart of patient inclusion). A total of 5942 of these patients had one or several of the diseases selected for this study. We excluded 47 patients because they did not have any appointments during the study period, leaving 5895 available for analysis.

During the study period, 363 patients died. The mean follow-up time was 1.9 years.

Of the 5895 patients, $65 \%$ (3838 patients) attended all their appointments and 35\% (2057 patients) missed one or several appointments in the two-year study period. The characteristics of patients with full attendance and patients with one or several occurrences of nonattendance are shown in Additional file 1.

\section{Results at the appointment level}

The included patients had a total of 82,898 appointments during the study period, of which 5\% (4393 appointments) were not attended (see Fig. 1: Flowchart of patient inclusion). A total of 195 appointments had occurrences of attendance and non-attendance on the same day; these were categorized as attendances.

The characteristics of patients who attended appointments and those who did not attend are shown in Table 1. There were significant differences in nearly all covariates between attendees and non-attendees. Those who did not attend appointments were more often young patients ( $40 \%$ vs. $19 \%$ aged $18-49 p<0.001)$, male $(58 \%$ vs. $52 \%$ $p<0.001)$, unmarried (53\% vs. $42 \% p<0.001)$ and low educated $(44 \%$ vs. $41 \%$ with only primary school education $p<0.001)$. Retired patients had the lowest non-attendance rate of the occupational groups (31\% vs. 53\%). Among the specific disease groups, patients with type 1 diabetes $(28 \%$ vs. $20 \% p<0.001$ ) had a higher non-attendance rate while a lower non-attendance rate was seen among patients with rheumatoid arthritis (11\% vs. $14 \% p<0.001)$ and osteoporosis $(4 \%$ vs. $8 \% p<0.001)$.

The results of the multivariate logistic regression are shown in Table 2. In our primary multivariate logistic model (a) young patients (aged $18 \leq 29$ years) had the highest odds of missing their appointments (odds ratio (OR) 4.17; 95\% confidence interval (CI) 2.70-6.42). Other significant predictors included middle-younger age (OR 2.58; CI 1.76-3.78 for $30 \leq 39$ years; OR 2.09; CI $1.47-2.98$ for $40 \leq 49$ years), the male gender (OR 1.35; CI 1.20-1.52), being unmarried (OR 1.39; CI 1.24-1.56), having a low educational level (OR 1.18; CI 1.01-1.40), and being on long-term welfare payments (OR 1.48; CI 1.13-1.93). There were no specific diseases associated with higher odds of missing appointments.

The secondary multivariate logistic regression (b) showed that patients undertaking several outpatient treatment courses were not significantly different from patients undertaking one outpatient treatment course.

\section{Discussion}

This study of patients undergoing routine hospital outpatient treatments for chronic diseases found that 35\% of patients had one or more occurrences of nonattendance and $5 \%$ of all appointments were not attended. Youth, the male gender, an unmarried status, low educational levels, and receipt of long-term welfare payments were all predictors of non-attendance. We did not find, that undergoing treatment for several chronic diseases simultaneously was a predictor for a higher rate of non-attendance.

We found a $5 \%$ rate of non-attendance, a lower rate than the average $23 \%$ reported in a newly published systematic review on non-attendance [5]. However, nonattendance rates show large differences across specialties as well as continents. For example, the median rate of non-attendance found by studies in cardiology was 30\%, while the median rate was $36 \%$ in endocrinology. However, researchers report that some studies define the non-attendance rate as including rescheduled or canceled appointments [5]. This naturally results in a higher rate than when non-attendance is defined only as appointments that have been missed, as we have used in our study. Our results are more consistent with Danish studies. Studies conducted in 2003 on several different Danish hospital outpatient clinics showed variations in non-attendance from 0 to $14 \%$, in average between 3 and 4\% [7]. A recent Danish study on radiology and orthopedic clinics likewise showed 4 and 5\% nonattendance rates, which were similar to our findings [6]. 


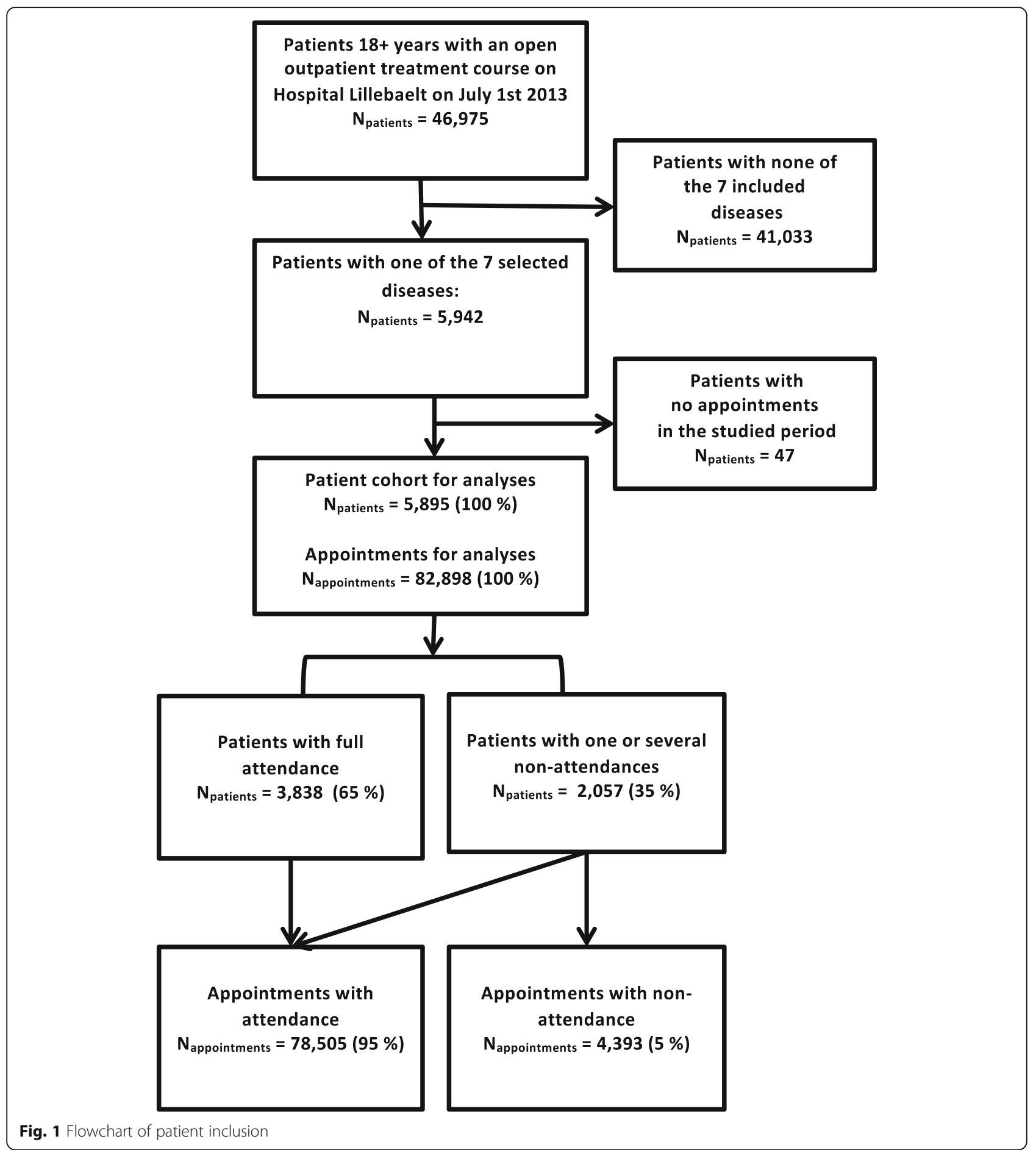

We think that the relatively low rate of nonattendance that we found, in contrast to international studies but concurrent with Danish studies, might be explained by factors such as age, geographical distance, and an aspect of culture. Although we found that young age was associated with higher non-attendance rates, confirming the results of other studies [5], the majority of patients in our study were elderly $(77 \%$ were 50 years or older) and, therefore, the overall non-attendance rate was lowered. Additionally, distance from the hospital has been associated with higher non-attendance rates [5], but the majority of patients in Denmark do not reside a long distance from the nearest hospital; for instance, in the hospital in our study the maximum travel time was $1 \mathrm{~h}$ by car. Further, in Denmark we have a good public transport system. The Danish study on radiology 
Table 1 Characteristics of appointments ( $n=82,898$ appointments)

\begin{tabular}{|c|c|c|c|c|c|c|c|}
\hline \multirow[t]{2}{*}{ Variable } & \multicolumn{2}{|l|}{ Total } & \multicolumn{2}{|c|}{ Appointments with attendance } & \multicolumn{2}{|c|}{ Appointments with non-attendance } & \multirow[t]{2}{*}{$p$-value } \\
\hline & $n$ & $\%$ & $n$ & $\%$ & $n$ & $\%$ & \\
\hline Overall & 82,898 & $100 \%$ & 78,505 & $100 \%$ & 4393 & $100 \%$ & \\
\hline Age & & & & & & & $<0.001$ \\
\hline $18-29$ & 2329 & $3 \%$ & 1925 & $2 \%$ & 404 & $9 \%$ & \\
\hline $30-39$ & 4682 & $6 \%$ & 4202 & $5 \%$ & 480 & $11 \%$ & \\
\hline $40-49$ & 10,629 & $13 \%$ & 9737 & $12 \%$ & 892 & $20 \%$ & \\
\hline $50-59$ & 15,989 & $19 \%$ & 15,072 & $19 \%$ & 917 & $21 \%$ & \\
\hline $60-69$ & 25,364 & $31 \%$ & 24,447 & $31 \%$ & 917 & $21 \%$ & \\
\hline $70-79$ & 18,659 & $23 \%$ & 18,055 & $23 \%$ & 604 & $14 \%$ & \\
\hline $80+$ & 5246 & $6 \%$ & 5067 & $6 \%$ & 179 & $4 \%$ & \\
\hline Gender & & & & & & & $<0.001$ \\
\hline male & 43,368 & $52 \%$ & 40,830 & $52 \%$ & 2538 & $58 \%$ & \\
\hline female & 39,530 & $48 \%$ & 37,675 & $48 \%$ & 1855 & $42 \%$ & \\
\hline Marital status & & & & & & & $<0.001$ \\
\hline Unmarried & 35,678 & $43 \%$ & 33,337 & $42 \%$ & 2341 & $53 \%$ & \\
\hline Married & 47,220 & $57 \%$ & 45,168 & $58 \%$ & 2052 & $47 \%$ & \\
\hline Educational level & & & & & & & $<0.001$ \\
\hline Basic (primary school) & 34,338 & $41 \%$ & 32,413 & $41 \%$ & 1925 & $44 \%$ & \\
\hline Vocational or upper secondary & 33,276 & $40 \%$ & 31,601 & $40 \%$ & 1675 & $38 \%$ & \\
\hline Further or higher education & 13,216 & $16 \%$ & 12,563 & $16 \%$ & 653 & $15 \%$ & \\
\hline Unknown & 2068 & $2 \%$ & 1928 & $2 \%$ & 140 & $3 \%$ & \\
\hline Occupational status & & & & & & & $<0.001$ \\
\hline Student & 706 & $1 \%$ & 599 & $1 \%$ & 107 & $2 \%$ & \\
\hline Affiliated to labour marked & 21,185 & $26 \%$ & 19,697 & $25 \%$ & 1488 & $34 \%$ & \\
\hline Short-term welfare payment & 2028 & $2 \%$ & 1844 & $2 \%$ & 184 & $4 \%$ & \\
\hline Long-term welfare payment & 2996 & $4 \%$ & 2646 & $3 \%$ & 350 & $8 \%$ & \\
\hline Disability pension & 12,435 & $15 \%$ & 11,649 & $15 \%$ & 786 & $18 \%$ & \\
\hline Pension & 42,742 & $52 \%$ & 41,359 & $53 \%$ & 1383 & $31 \%$ & \\
\hline Unknown & 806 & $1 \%$ & 711 & $1 \%$ & 95 & $2 \%$ & \\
\hline \multicolumn{8}{|l|}{ Specific chronic disease } \\
\hline Type 1 diabetes mellitus & & & & & & & $<0.001$ \\
\hline yes & 17,310 & $21 \%$ & 16,093 & $20 \%$ & 1217 & $28 \%$ & \\
\hline no & 65,588 & $79 \%$ & 62,412 & $80 \%$ & 3176 & $72 \%$ & \\
\hline Type 2 diabetes mellitus & & & & & & & 0.53 \\
\hline yes & 36,629 & $44 \%$ & 34,762 & $44 \%$ & 1867 & $42 \%$ & \\
\hline no & 46,269 & $56 \%$ & 43,743 & $56 \%$ & 2526 & $58 \%$ & \\
\hline Hearth failure & & & & & & & 0.15 \\
\hline yes & 4129 & $5 \%$ & 3928 & $5 \%$ & 201 & $5 \%$ & \\
\hline no & 78,769 & $95 \%$ & 74,577 & $95 \%$ & 4192 & $95 \%$ & \\
\hline COPD & & & & & & & 0.53 \\
\hline yes & 4854 & $6 \%$ & 4582 & $6 \%$ & 272 & $6 \%$ & \\
\hline no & 78,044 & $94 \%$ & 73,923 & $94 \%$ & 4121 & $94 \%$ & \\
\hline Asthma & & & & & & & 0.13 \\
\hline yes & 5062 & $6 \%$ & 4746 & $6 \%$ & 316 & $7 \%$ & \\
\hline
\end{tabular}


Table 1 Characteristics of appointments ( $n=82,898$ appointments) (Continued)

\begin{tabular}{|c|c|c|c|c|c|c|c|}
\hline \multirow[t]{2}{*}{ Variable } & \multicolumn{2}{|l|}{ Total } & \multicolumn{2}{|c|}{ Appointments with attendance } & \multicolumn{2}{|c|}{ Appointments with non-attendance } & \multirow[t]{2}{*}{$p$-value ${ }^{1}$} \\
\hline & $n$ & $\%$ & $\mathrm{n}$ & $\%$ & $n$ & $\%$ & \\
\hline no & 77,836 & $94 \%$ & 73,759 & $94 \%$ & 4077 & $93 \%$ & \\
\hline Rheumatorid arthritis & & & & & & & $<0.001$ \\
\hline yes & 11,621 & $14 \%$ & 11,154 & $14 \%$ & 467 & $11 \%$ & \\
\hline no & 71,277 & $86 \%$ & 67,351 & $86 \%$ & 3926 & $89 \%$ & \\
\hline Osteoporosis & & & & & & & $<0.001$ \\
\hline yes & 6496 & $8 \%$ & 6300 & $8 \%$ & 196 & $4 \%$ & \\
\hline no & 76,402 & $92 \%$ & 72,205 & $92 \%$ & 4197 & $96 \%$ & \\
\hline Number of outpatient treatment courses & & & & & & & 0.32 \\
\hline 1 & 79,719 & $96 \%$ & 75,468 & $96 \%$ & 4251 & $97 \%$ & \\
\hline $2+$ & 3179 & $4 \%$ & 3037 & $4 \%$ & 142 & $3 \%$ & \\
\hline
\end{tabular}

'Univariate mixed effects logistic regression model for 'appointments with attendance' versus 'appointment with non-attendance' with a random effect taking appointments of the same paitent into account

and orthopedic clinics included travel time in their investigation and found no association with higher nonattendance rates [6].

We suspect there may be a cultural aspect to these findings as well, in that Danes, for the most part, either attend or give notice when they have an appointment. We find it notable that Danish patients are not charged a fee for non-attendance, and at the time this study was conducted, neither did they receive a reminder about appointments prior to the day of attendance.

We found several significant predictors for nonattendance. Our findings are concurrent with the systematic review by Dantas and colleagues that showed that young age and low socioeconomic status are predictors for non-attendances [5]. With regard to gender and marital status the review showed that the majority of studies did not find any statistical differences between these factors in relation to non-attendance. However, the few studies that did find a difference, are concurrent with our findings, that male gender and unmarried status are predictive factors for a higher non-attendance rate.

The novel finding of this study - that patients undertaking several outpatient treatment courses do not have higher rates of non-attendance - is surprising as we hypothesized that patients with several hospital outpatient treated diseases may have several appointments to keep in different clinics, and therefore, would require a higher degree of coordination, which could cause a greater rate of non-attendance. Our finding contradicts this, and we reflect that patients treated for long-term chronic diseases may be used to the routine of attendance. It can be the on-going relation with the health care team that nurses them to come or maybe their diseases are more severe and medical assistance such as medicine adjustments are required more often and motivates this patient group to show up.

\section{Strengths and limitations}

Our study has important strengths. First, it included all patients undergoing hospital outpatient treatment for the selected diseases at Hospital Lillebaelt. Second - information from other registries for all patients was available because of the unique identification number. Third, the diagnoses in NPR are generally of high validity [31]. Of the diagnoses we included, only osteoporosis has not been validated in a hospital outpatient setting. The positive predictive value (PPV) for each of the other diagnoses is as follows: type 1 diabetes and type 2 diabetes $(\mathrm{PPV}=96.0(86.5-98.9))$, heart failure (PPV = 100 (92.9$100))$, COPD $(\mathrm{PPV}=100(92.9-100))$, asthma $(\mathrm{PPV}=$ $65.3(62.2-68.3)$ ), and rheumatoid arthritis (PPV $=98.0$ (89.5-100)) [31]. Third, we had a large study sample including patients from different hospital clinics.

However, there are also some limitations to our study. First, it is based on administrative data. As all attended appointments are financially reimbursed by the government, we presume that the data are complete. In contrast, appointments without attendance are not financially reimbursed, and although there is a policy at Hospital Lillebaelt of documenting non-attendance, we cannot be sure, that it is always registered correctly. A limitation is also the possibility of non-attendance being caused by hospital admission, though admissions are often known in the documenting process of nonattendance. Further, the database of Lillebaelt does not record missed appointments that would have provided the first contact for a new outpatient treatment course. This possibly introduced a component of measurement bias to the study, resulting in the under- or overestimation of the reported rate. However, the predictors would presumably have remained unaffected, as the bias would have been equally distributed within the groups of attendees and non-attendees, thereby retaining their 
Table 2 Appointment characteristic associated with non-attendences. Results of univariate and multivariate analysis for all variables: Odds ratios and their 95\% conficence interval ( $n=82,898$ appointments)

\begin{tabular}{|c|c|c|c|c|c|c|}
\hline & \multicolumn{2}{|c|}{ Univariate analysis } & \multicolumn{2}{|c|}{ Multivariate analysis $^{a}$} & \multicolumn{2}{|c|}{ Multivariate analysis $^{\mathrm{b}}$} \\
\hline & $\mathrm{OR}$ & $(95 \% \mathrm{Cl})$ & $\mathrm{OR}$ & $(95 \% \mathrm{Cl})$ & $\mathrm{OR}$ & $(95 \% \mathrm{Cl})$ \\
\hline \multicolumn{7}{|l|}{ Age } \\
\hline $18-29$ & $5.97^{*}$ & $4.28-8.33$ & $4.17^{*}$ & $2.70-6.42$ & $4.01 *$ & $2.63-6.11$ \\
\hline $30-39$ & $3.25^{*}$ & $2.41-4.39$ & $2.58^{*}$ & $1.76-3.78$ & $2.51^{*}$ & $1.73-3.66$ \\
\hline $40-49$ & $2.69^{*}$ & $2.06-3.53$ & $2.09^{*}$ & $1.47-2.98$ & $2.06^{*}$ & $1.45-2.93$ \\
\hline $50-59$ & $1.53^{*}$ & $1.18-1.99$ & 1.20 & $0.85-1.69$ & 1.18 & $0.84-1.67$ \\
\hline $60-69$ & 0.87 & $0.68-1.13$ & 0.88 & $0.68-1.15$ & 0.88 & $0.67-1.15$ \\
\hline $70-79$ & 0.85 & $0.65-1.11$ & 0.90 & $0.69-1.18$ & 0.90 & $0.69-1.18$ \\
\hline $80+$ & 1 & & 1 & & 1 & \\
\hline \multicolumn{7}{|l|}{ Gender } \\
\hline Male & $1.36^{*}$ & $1.21-1.53$ & $1.35^{*}$ & $1.20-1.52$ & $1.44^{*}$ & $1.29-1.61$ \\
\hline Female & 1 & & 1 & & 1 & \\
\hline \multicolumn{7}{|l|}{ Marital status } \\
\hline Unmarried & $1.67^{*}$ & $1.49-1.88$ & $1.39^{*}$ & $1.24-1.56$ & $1.40^{*}$ & $1.25-1.57$ \\
\hline Married & 1 & & 1 & & 1 & \\
\hline \multicolumn{7}{|l|}{ Educational level } \\
\hline Basic (primary school) & 1.14 & $0.96-1.35$ & $1.18^{*}$ & $1.01-1.40$ & $1.21^{*}$ & $1.03-1.43$ \\
\hline Vocational or upper secondary & 1.00 & $0.85-1.18$ & 0.95 & $0.81-1.12$ & 0.96 & $0.82-1.13$ \\
\hline Further or higher education & 1 & & 1 & & 1 & \\
\hline Unknown & $1.67^{*}$ & $1.16-2.42$ & $1.71^{*}$ & $1.21-2.42$ & $1.77^{*}$ & $1.25-2.50$ \\
\hline \multicolumn{7}{|l|}{ Occupational status } \\
\hline Student & $2.24^{*}$ & $1.40-3.59$ & 0.83 & $0.50-1.38$ & 0.83 & $0.50-1.38$ \\
\hline Affiliated to labor marked & 1 & & 1 & & 1 & \\
\hline Short-term welfare payment & $1.59^{*}$ & $1.13-2.23$ & 1.32 & $0.95-1.83$ & 1.35 & $0.97-1.89$ \\
\hline Long-term welfare payment & $1.88^{*}$ & $1.44-2.45$ & $1.48^{*}$ & $1.13-1.93$ & $1.50^{*}$ & $1.15-1.95$ \\
\hline Disability pension & 0.96 & $0.80-1.14$ & 1.08 & $0.90-1.30$ & 1.12 & $0.93-1.34$ \\
\hline Pension & $0.43^{*}$ & $0.38-0.49$ & $0.75^{*}$ & $0.59-0.96$ & $0.76^{*}$ & $0.59-0.97$ \\
\hline Unknown & 2.13 & $1.31-3.46$ & $1.99^{*}$ & $1.24-3.19$ & $2.05^{*}$ & $1.27-3.30$ \\
\hline \multicolumn{7}{|l|}{ Specific diseases } \\
\hline \multicolumn{7}{|l|}{ Type 1 diabetes mellitus } \\
\hline yes & $1.75^{*}$ & $1.53-2.01$ & 1.04 & $0.73-1.48$ & & \\
\hline no & 1 & & 1 & & & \\
\hline \multicolumn{7}{|l|}{ Type 2 diabetes mellitus } \\
\hline yes & 0.96 & $0,86-1,08$ & 1.14 & $0.81-1.59$ & & \\
\hline no & 1 & & 1 & & & \\
\hline \multicolumn{7}{|l|}{ Hearth failure } \\
\hline yes & 0,81 & $0,61-1,08$ & 1.16 & $0.78-1.70$ & & \\
\hline no & 1 & & 1 & & & \\
\hline \multicolumn{7}{|l|}{ COPD } \\
\hline yes & 1,08 & $0,85-1,36$ & 1.44 & $0.99-2.10$ & & \\
\hline no & 1 & & 1 & & & \\
\hline \multicolumn{7}{|l|}{ Asthma } \\
\hline yes & 1,19 & $0,95-1,49$ & 0.96 & $0.66-1.41$ & & \\
\hline
\end{tabular}


Table 2 Appointment characteristic associated with non-attendences. Results of univariate and multivariate analysis for all variables: Odds ratios and their 95\% conficence interval ( $n=82,898$ appointments) (Continued)

\begin{tabular}{|c|c|c|c|c|c|c|}
\hline & \multicolumn{2}{|c|}{ Univariate analysis } & \multicolumn{2}{|c|}{ Multivariate analysis $^{\mathrm{a}}$} & \multicolumn{2}{|c|}{ Multivariate analysis ${ }^{\mathrm{b}}$} \\
\hline & OR & $(95 \% \mathrm{Cl})$ & OR & $(95 \% \mathrm{Cl})$ & OR & $(95 \% \mathrm{Cl})$ \\
\hline no & 1 & & 1 & & & \\
\hline \multicolumn{7}{|c|}{ Rheumatorid arthritis } \\
\hline yes & $0,71^{*}$ & $0,60-0,85$ & 0.95 & $0.67-1.34$ & & \\
\hline no & 1 & & 1 & & & \\
\hline \multicolumn{7}{|c|}{ Osteoporosis } \\
\hline yes & $0,43^{*}$ & $0,34-0,54$ & 0.79 & $0.54-1.15$ & & \\
\hline no & 1 & & 1 & & & \\
\hline \multicolumn{7}{|c|}{ Number of outpatient treatment courses } \\
\hline 1 & 1 & & & & 1 & \\
\hline $2+$ & 0,84 & $0,59-1,19$ & & & 1.05 & $0.76-1.46$ \\
\hline
\end{tabular}

proportions. Additionally, we chose to categorize information on patients who attended an appointment and missed an appointment on the same day under attended appointments. As this was the case for only 195 appointments, it could not have biased the results. Nonetheless, a limitation can be found in that the collection of information on predictors was extracted on July 1, 2013, thereby earlier than the actual appointments. This may have resulted in an under- or overestimation of the "number of outpatient treatment courses." We presume that variations in the other predictors have not greatly affected the overall results as they are unlikely to have varied significantly over the two-year study period.

While we set out to investigate the effect of having multiple chronic diseases on the rate of non-attendance, we only investigated diseases treatment at hospital outpatient level. Patients may have other chronic diseases that they undergo treatment for in primary care. Therefore, we can only investigate the effect of having multiple chronic diseases at a hospital outpatient level.

In this study we investigated factors we could extract from the administrative system which do not contain information on patient reported outcome measures. Information regarding the patient's perception could be investigated by means of qualitative interviews. We did not investigate if visits were in the form of face-to-face meeting, telephone consultations or other kind of telehealth communication which could have been relevant for subgroup analysis. Furthermore, it was not possible to divide appointments based on their purpose, e.g., acute appointment; evaluate a medication dosage change; routine follow-up to monitor chronic conditions; etc. which is a limitation.

Finally, hospital Lillebaelt has a rural and urban catchment population that covers $5 \%$ of the Danish population, but other Danish hospitals may differ in catchment population. However, overall we find our conclusions applicable to other Danish hospitals and health-care systems like the Danish.

\section{Clinical implications}

This study showed that Danish patients with chronic diseases miss one in every 20 appointments (5\%). A major part of hospital outpatient activity involves patients in treatment for chronic diseases and nonattendance by members of this group is very inefficient for the hospital. Further, perhaps especially for patients with chronic conditions, continuity of care is an important aspect and non-attendance interrupts this continuity. Therefore, we argue that a further reduction in the nonattendance rate is important.

The results from our study on chronic patients in hospital outpatient clinics can be made operational in a number of ways. Knowledge about predictors for potential non-attenders can assist in targeted interventions; for example, studies on outpatient reminder systems have shown that they reduce non-attendance [12, 37]. In a hospital were such a system has been implemented it is relevant to investigate to what extent this affects nonattendance rates among chronic patient groups.

In this study we investigated the extent of nonattendance for patients in long-term treatment and some factors for non-attendance. Information regarding mechanisms on why these patients do not attend their appointments by qualitative methods should be obtained e.g., if non-attendance is caused by forgetfulness a reminder system could help, but patients may miss appointments for other reasons that are important to discover if we wish to find better ways to organize their treatment courses. 
A final note on the clinical implication of this study regards the clinical relevance of the prognostic factors. We find our results robust because of the relatively large sample size. It is however for the interested clinic or hospital management to decide which prognostic factors are of clinical relevance which will depend on factors such as context and population size.

\section{Conclusion}

In conclusion, our study showed that among the group of patients in hospital outpatient treatment for chronic disease one in every 20 appointments (5\%) resulted in non-attendance. We found several predictors for nonattendance including youth, male gender, unmarried status, low educational level, and the receipt of long-term welfare payments. We found no specific patient groups associated with a higher non-attendance rate. Neither did patients treated for several chronic diseases have a higher rate of non-attendance than patients in hospital outpatient treatment for a single chronic disease. As continuity of care is important for patients with chronic diseases and non-attendance is inefficient for the health care system our findings can be used to assist in targeting groups for interventions to reduce the nonattendance rate. Nonetheless, further research on why these chronic patients miss appointments is required.

\section{Additional file}

Additional file 1: "Characteristics of patients with full attendance (attenders) and partial attendance (non-attenders) during the two year study period ( $n=5,895$ patients)". (PDF $45 \mathrm{~kb}$ )

\section{Abbreviations}

AIC: Akaike information criterion; COPD: Chronic obstructive pulmonary disease

\section{Acknowledgements}

The authors wish to thank Hans Jørn Refgaard Jørgensen, special consultant from Hospital Lillebaelt for providing data about non-attendance for this article. Furthermore, we wish to express our gratitude to associate professor, PhD, Sören Möller, Statistician from OPEN for statistical support with this article.

\section{Authors' contributions}

DLW, CBM, FBW and KHR designed the study. DLW and KHR performed the data preparation. DLW analyzed the data. KHR, FBW, KCH, SBB, CBM, TLS and CVP contributed to data interpretation. All authors read, commented and approved the final manuscript

\section{Funding}

This work was supported in part by a Grant from, 'Knud og Edith Eriksens Mindefond'. The funding source played no role in the study design, the collection, analysis, or in the interpretation of data.

\section{Availability of data and materials}

The data that support the findings of this study are available at Statistic Denmark, but restrictions apply to the availability of these data, which were used under license for the current study, and so are not publicly available. Data are however available from the authors upon reasonable request and with permission of the Danish Data Protection Agency and Statistic Denmark.

\section{Ethics approval and consent to participate}

The study was a register-based study which did not involve any direct contact with the patients or access to patient files, thus no informed consent or ethical approval was required. The study was registered with the Danish Data Protection Agency (Project ID 18/35695).

\section{Consent for publication}

Not applicable.

\section{Competing interests}

The authors declare that they have no competing interests.

\section{Author details}

${ }^{1}$ Hospital of Southern Denmark, DK-6200 Aabenraa, Denmark. ²Department of Regional Health Research, University of Southern Denmark, Winsløwparken 19, DK-5000 Odense C, Denmark. ${ }^{3}$ Research Unit of General Practice, Department of Public Health, University of Southern Denmark, Odense, Denmark. ${ }^{4}$ Direction Général de la Santé and Unisanté, Lausanne, Switzerland. ${ }^{5}$ Department of Clinical Research, University of Southern Denmark, Odense, Denmark. ${ }^{6}$ The Danish Patient Safety Authority, Kolding, Denmark. ${ }^{7}$ Department of Vascular Surgery, Kolding Hospital, Part of Hospital Lillebaelt, Kolding, Denmark. ${ }^{8}$ OPEN-Open Patient data Explorative Network - Department of Clinical Research and Odense University Hospital, Region of Southern Denmark, Odense, Denmark.

Received: 9 October 2018 Accepted: 31 May 2019

Published online: 14 June 2019

\section{References}

1. Hwang AS, Atlas SJ, Cronin P, Ashburner JM, Shah SJ, He W, et al. Appointment "no-shows" are an independent predictor of subsequent quality of care and resource utilization outcomes. J Gen Intern Med. 2015; 30(10):1426-33.

2. Nuti LA, Lawley M, Turkcan A, Tian Z, Zhang L, Chank K, et al. No-shows to primary care appointments: subsequent acute care utilization among diabetic patients. BMC Health Serv Res. 2012;12:304.

3. Rhee MK, Slocum W, Ziemer DC, Culler SD, Cook CB, El-Kebbi IM, et al. Patient adherence improves glycemic control. Diabetes Educ. 2005;31(2): 240-50.

4. Karter AJ, Parker MM, Moffet HH, Ahmed AT, Ferrara A, Liu JY, et al. Missed appointments and poor glycemic control: an opportunity to identify highrisk diabetic patients. Med Care. 2004:42(2):110-5.

5. Dantas LF, Fleck JL, Cyrino Oliveira FL, Hamacher S. No-shows in appointment scheduling - a systematic literature review. Health Policy. 2018; 122(4):412-21

6. Blaehr EE, Sogaard R, Kristensen T, Vaeggemose U. Observational study identifies non-attendance characteristics in two hospital out-patient clinics. Dan Med J. 2016:63:A5283.

7. Ministry of Finance. Report from the working group on payment for nonattending appointments in the public health care sector [rapport fra arbejdsgruppen vedr. Betaling ved udeblivelse fra aftaler med det offentlige] 2004 [in Danish]; Available from: https://www.fm.dk/ publikationer/2004/rapport-fra-arbejdsgruppen-vedr-betaling-vedudeblivelse Acessed 29 Sep 2018

8. Guedes R, Leite I, Baptista A. Dermatology missed appointments: an analysis of outpatient non-attendance in a general hospital's population. Int J Dermatol. 2014:53(1):39-42.

9. Sola-vera J, Saez J, Laveda R, Girona E, Garcia-Sepulcre MF, Cuesta A, et al. Factors associated with non-attendance at outpatient endoscopy. Scand J Gastroenterol. 2008;43(2):202-6.

10. Dyer PH, Lloyd CE, Lancashire RJ, Bain SC, Barnett AH. Factors associated with clinic non-attendance in adults with type 1 diabetes mellitus. Diabet Med. 1998;15(4):339-43.

11. Chang JT, Sewell JL, Day LW. Prevalence and predictors of patient no-shows to outpatient endoscopic procedures scheduled with anesthesia. BMC Gastroenterol. 2015;15:123.

12. Parikh A, Gupta K, Wilson AC, Fields K, Cosgrove NM, Kostis JB. The effectiveness of outpatient appointment reminder systems in reducing noshow rates. Am J Med. 2010;123(6):542-8. 
13. Barnett K, Mercer SW, Norbury M, Watt G, Wyke S, Guthrie B. Epidemiology of multimorbidity and implications for health care, research, and medical education: a cross-sectional study. Lancet. 2012;380(9836):37-43.

14. Ward BW, Schiller JS. Prevalence of multiple chronic conditions among US adults: estimates from the National Health Interview Survey. Prev Chronic Dis. 2010;2013(10):E65.

15. Orueta JF, García-Álvarez A, García-Goñi M, Paolucci F, Nuño-Solinís R. Prevalence and costs of multimorbidity by deprivation levels in the Basque Country: a population based study using health administrative databases. PLoS One. 2014;9(2):e89787.

16. van Oostrom SH, Gijsen R, Stirbu I, Korevaar JC, Schellevis FG, Picavet HS, et al. Time trends in prevalence of chronic diseases and multimorbidity not only due to aging: data from general practices and health surveys. PLoS One. 2016;11(8):e0160264.

17. Gerteis J, Izrael D, Deitz D, LeRoy L, Ricciardi R, Miller T, Basu J. Multiple Chronic Conditions Chartbook. 2014; Available from: https://www.ahrq.gov/ sites/default/files/wysiwyg/professionals/prevention-chronic-care/decision/ mcc/mccchartbook.pdf accessed 29 Sep 2018.

18. Kingston $\mathrm{A}$, Robinson $\mathrm{L}$, Booth $\mathrm{H}$, Knapp $\mathrm{M}$, Jagger $\mathrm{C}$, MODEM project. Projections of multi-morbidity in the older population in England to 2035: estimates from the population ageing and care simulation (PACSim) model. Age Ageing. 2018;47(3):374-80.

19. Rijken M, Struckmann V, Dyakova M, Melchiorre MG, Rissanen S, van Ginneken E. ICARE4EU: improving care for people with multiple chronic conditions in Europe Eurohealth incorporating Euro Observer. 2013;19(3): 29-31.

20. Pruitt SD, Epping-Jordan JE. Preparing the 21st century global healthcare workforce. BMJ. 2005;330(7492):637-9.

21. Nolte, E. and M. McKee. Caring for people with chronic conditions. A health system perspective. 2008; Available from: http://www.euro.who.int/_data/ assets/pdf_file/0006/96468/E91878.pdf. Accessed 29 Sep 2018.

22. Eriksen MF, Kjellberg J. Reducing non-attendance in the health care system: an international literature study [Nedbringelse af udeblivelser i sundhedsvæsenet : international litteraturstudie]. 2013; Available from: https://pure.vive.dk/ws/files/2043897/nedbringelse-af-udeblivelser-isundhedsvaesnet-\%E2\%80\%93-internationalt-litteraturstudie.pdf. Accessed 26 Feb 2019.

23. The Danish health authority. Treatment programs for chronic diseases - the generic model [Forløbsprogrammer for kronisk sygdom - den generiske model]. 2012 [in Danish].

24. The Ministry of Health. Healthcare in Denmark : an overview. 2016; Available from: https://www.sum.dk/ /media/Filer\%20-\%20Publikationer_i_pdf/2016/ Healthcare-in-dk-16-dec/Healthcare-english-V16-dec.pdf Accessed 29 Sept 2018.

25. Daggy J, Lawley M, Willis D, Thayer D, Suelzer C, DeLaurentis PC, et al. Using no-show modeling to improve clinic performance. Health Informatics J. 2010;16(4):246-59.

26. National Institute of Public Health, Eight public health diseases - prevalence and development [Otte Folkesygdomme - forekomst og udvikling]. 2005 [in Danish].

27. Flachs E, Eriksen L, Koch M, Ryd J, Dibba E, Skov-Ettrup L, et al. Diseaseburden in Denmark: Diseases [Sygdomsbyrden i Danmark: sygdomme]. 2015 [in Danish]; Available from: https://www.sst.dk/da/ sygdom-og-behandling/ /media/00C6825B11BD46F9B064536C6E7DFBA0. ashx. Accessed 29 Sept 2018.

28. Wolff DL, von Plessen C, Waldorff FB, Sorensen TL, Bogh SB, Rubin KH, et al. Time trends in patients managed simultaneously in multiple hospital outpatient specialty clinics for chronic diseases: A register-based crosssectional study. J Comorb. 2019:9:2235042X19831907.

29. Hospital Lillebaelt. Hospital Lillebaelt [Sygehus Lillebælt]. 2018 [in Danish]. Available from: http://fremtidenssygehuse.dk/wm290560. Accessed 29 Sept 2018.

30. Statistics Denmark. Population count 2018 [Folketal 2018]. 2018 [in Danish]; Available from: https://www.dst.dk/da/Statistik/emner/befolkning-og-valg/ befolkning-og-befolkningsfremskrivning/folketal. Accessed 29 Sept 2018.

31. Schmidt M, Schmidt SA, Sandegaard JL, Ehrenstein V, Pedersen L, Sorensen HT. The Danish National Patient Registry: a review of content, data quality, and research potential. Clin Epidemiol. 2015;7:449-90.

32. Lynge E, Sandegaard JL, Rebolj M. The Danish National Patient Register. Scand J Public Health. 2011;39(7 Suppl):30-3.

33. Pedersen CB. The Danish civil registration system. Scand J Public Health 2011;39(7 Suppl):22-5.
34. Jensen VM, Rasmussen AW. Danish education registers. Scand J Public Health. 2011;39(7 Suppl):91-4.

35. Baadsgaard M, Quitzau J. Danish registers on personal income and transfer payments. Scand J Public Health. 2011;39(7 Suppl):103-5.

36. The Regional Committees on Health Research Ethics for Southern Denmark. Research trials that do not require approval [Forsøgstyper uden anmeldelsespligt]. 2018 [in Danish]; Available from: https://komite. regionsyddanmark.dk/wm428123. Accessed 29 Sept 2018.

37. Stubbs ND, Geraci SA, Stephenson PL, Jones DB, Sanders S. Methods to reduce outpatient non-attendance. Am J Med Sci. 2012;344(3):211-9.

\section{Publisher's Note}

Springer Nature remains neutral with regard to jurisdictional claims in published maps and institutional affiliations.
Ready to submit your research? Choose BMC and benefit from:

- fast, convenient online submission

- thorough peer review by experienced researchers in your field

- rapid publication on acceptance

- support for research data, including large and complex data types

- gold Open Access which fosters wider collaboration and increased citations

- maximum visibility for your research: over $100 \mathrm{M}$ website views per year

At BMC, research is always in progress.

Learn more biomedcentral.com/submissions 